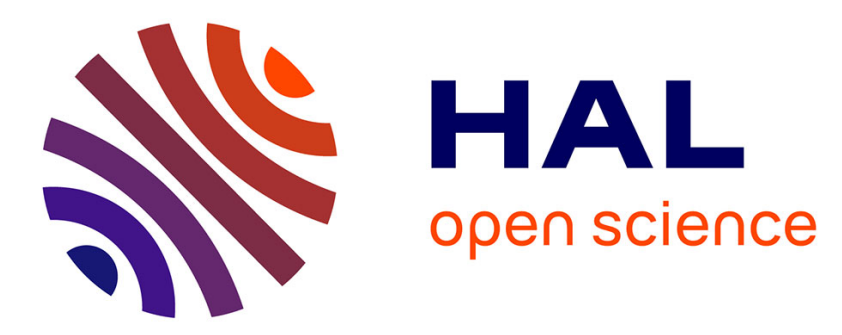

\title{
An approximate two-dimensional transient analysis of charge transport in a buried-channel charge-coupled device
}

\author{
R.S. Ferguson, W.D. Ryan
}

\section{- To cite this version:}

R.S. Ferguson, W.D. Ryan. An approximate two-dimensional transient analysis of charge transport in a buried-channel charge-coupled device. Revue de Physique Appliquée, 1978, 13 (12), pp.683-690. 10.1051/rphysap:019780013012068300 • jpa-00244526

HAL Id: jpa-00244526

https://hal.science/jpa-00244526

Submitted on 1 Jan 1978

HAL is a multi-disciplinary open access archive for the deposit and dissemination of scientific research documents, whether they are published or not. The documents may come from teaching and research institutions in France or abroad, or from public or private research centers.
L'archive ouverte pluridisciplinaire $\mathbf{H A L}$, est destinée au dépôt et à la diffusion de documents scientifiques de niveau recherche, publiés ou non, émanant des établissements d'enseignement et de recherche français ou étrangers, des laboratoires publics ou privés. 


\title{
CHARGE COUPLED DEVICES.
}

\section{AN APPROXIMATE TWO-DIMENSIONAL TRANSIENT ANALYSIS OF CHARGE TRANSPORT IN A BURIED-CHANNEL CHARGE-COUPLED DEVICE}

\author{
R. S. FERGUSON and W. D. RYAN \\ Dept. of Electronic Engineering, Queen's University of Belfast, Ashby Building, Stranmillis Road, \\ Belfast, BT9 5AH, N. Ireland
}

\begin{abstract}
Résumé. - On présente un procédé pour l'analyse approchée transitoire du BCCD. La solution est obtenue en considérant seulement l'équation presque linéaire de Poisson/Laplace dans une région complètement vide/charge-neutre et le calcul subséquent du passage des " trous " à travers la surface entre deux faces entre la région chargée et la région neutre. Des facteurs supplémentaires sont introduits dans la solution pour assurer le maintien de l'uniformité du courant et la consersation de la charge. Ainsi des raisons qui aboutissent à de petites insuffisances de décalage de charge ne peuvent pas être démontrées. Un exemple est présenté en montrant l'action du recouvrement de clock waveform sur la méthode du déplacement de charge. En outre des distributions quasi statiques de l'énergie potentielle sont confrontées avec une analyse à une dimension et en état soutenu.
\end{abstract}

\begin{abstract}
A method for the approximate transient analysis of the BCCD is presented. The solution is obtained by considering only the nearly-linear Poisson/Laplace's equation in a completelydepleted/charge-neutral region and subsequent estimate of carrier flow across the interface between the charged and neutral regions. Additional factors are introduced in the solution of the equations to ensure that current continuity and charge conservation are maintained. Hence mechanisms leading to small transfer inefficiencies cannot be represented. An example is presented showing the effect of clock waveform overlap on the transfer process. In addition quasi static potential and charge distributions are compared with a one-dimensional steady state exact simulation.
\end{abstract}

1. Introduction. - Bulk Channel Charge Coupled Devices (BCCD) as an addition to the family of CCD's originally proposed by Boyle and Smith [1] exhibit characteristics not normally found in surface CCD's e.g. high speed of operation. Thus they compliment the surface device and allow the circuit designer an alternative for specialised applications. Waldren et al. [2] discuss the advantages that can be gained from such structures and the principles of operation. As with any semiconductor device it is important to understand its operation, advantages and limitations. Several authors have studied the bulk structure, McKenna and Schryer [3, 4] considered the potential and field profile with no mobile carriers. El-Sissi and Cobbold $[5,6]$ proposed a model which divided the device into regions and solved approximations to Poisson's equation in each, Kent [7] studied the charge distribution in a one-dimensional structure.

As the channel of a BCCD cannot be approximated as an infinitely thin layer existing at the $\mathrm{Si} / \mathrm{SiO}_{2}$ interface the one-dimensional model which has been used for surface device analysis is not applicable for the evaluation of channel fields, operating frequencies and transfer inefficiency. To obtain a reasonable picture of device operation a two-dimensional transient analysis is required. Basing such an analysis on the numerical solution of the Poisson/Continuity equations system is very demanding both in computer time and storage requirements. If a significant reduction in accuracy is acceptable, an approximate transient solution may be obtained. In this paper such a method will be outlined and where possible the approximations will be validated by comparison with a onedimensional steady state solution of the semiconductor equation's system.

2. Potential solution with no mobile charge. If depletion depth can be specified then a solution of Poisson's equation will give the potential within the device, Magowan and Armstrong [8, 9] proposed such a procedure for the analysis of the MOST in which the position of the depletion/neutral boundary $X X^{\prime}$ (Fig. 1a) is determined as an integral part of the solution. The required boundary conditions on $X X^{\prime}$ are :

$$
\psi=\psi_{\mathrm{ss}}
$$

and

$$
E_{\mathrm{n}}=0
$$

where $\psi_{\mathrm{ss}}$ is the substrate potential and $E_{\mathrm{n}}$ the normal component of field on the boundary.

If the surface channel and the input and output diffusions are removed and several additional gates deposited on the oxide surface the structure becomes equivalent to a group of MOS capacitors, operating in deep depletion regime (Fig. 1b). Including an epitaxial layer of opposite doping type and assuming total 


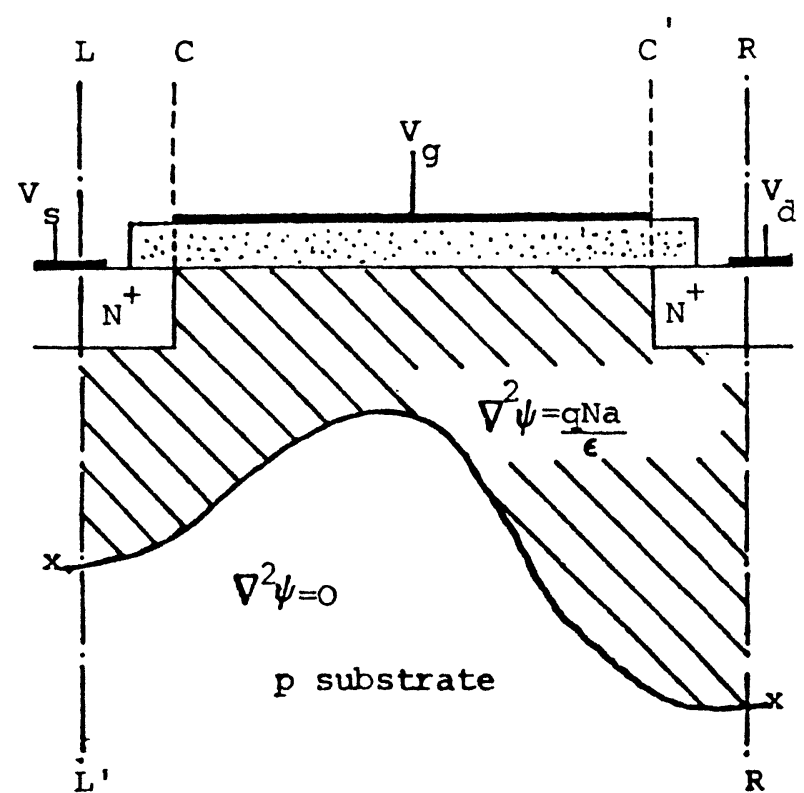

a)
FIG. 1. - a) MOS Transistor structure after Magowan and Armstrong $[7,8]$ with boundary conditions, $\psi=\psi_{\mathrm{s}}, E_{\mathrm{n}}=0$ on $X X^{\prime}$ and $\left(\psi / \hat{c} x=0\right.$ at $L L^{\prime}$ and $\left.R R^{\prime} . b\right)$ Three adjacent MOS capacitors on p substrate $\left|V_{\mathbf{g} 2}\right| \gg\left|V_{\mathrm{g} 1}\right|>\left|V_{\mathrm{g} 3}\right|$ with deep depletion boundary $X X^{\prime}$, and surface potential $\varphi_{\mathrm{s}}$ versus distance.
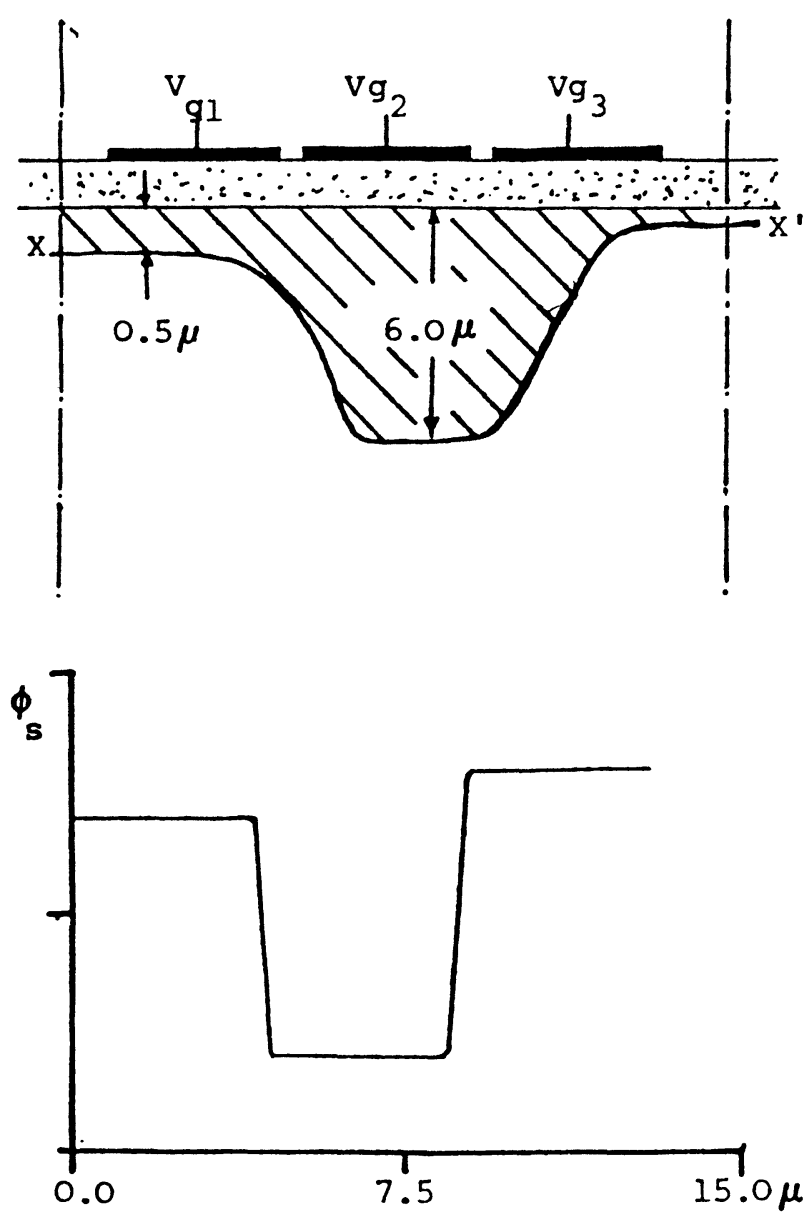

b)

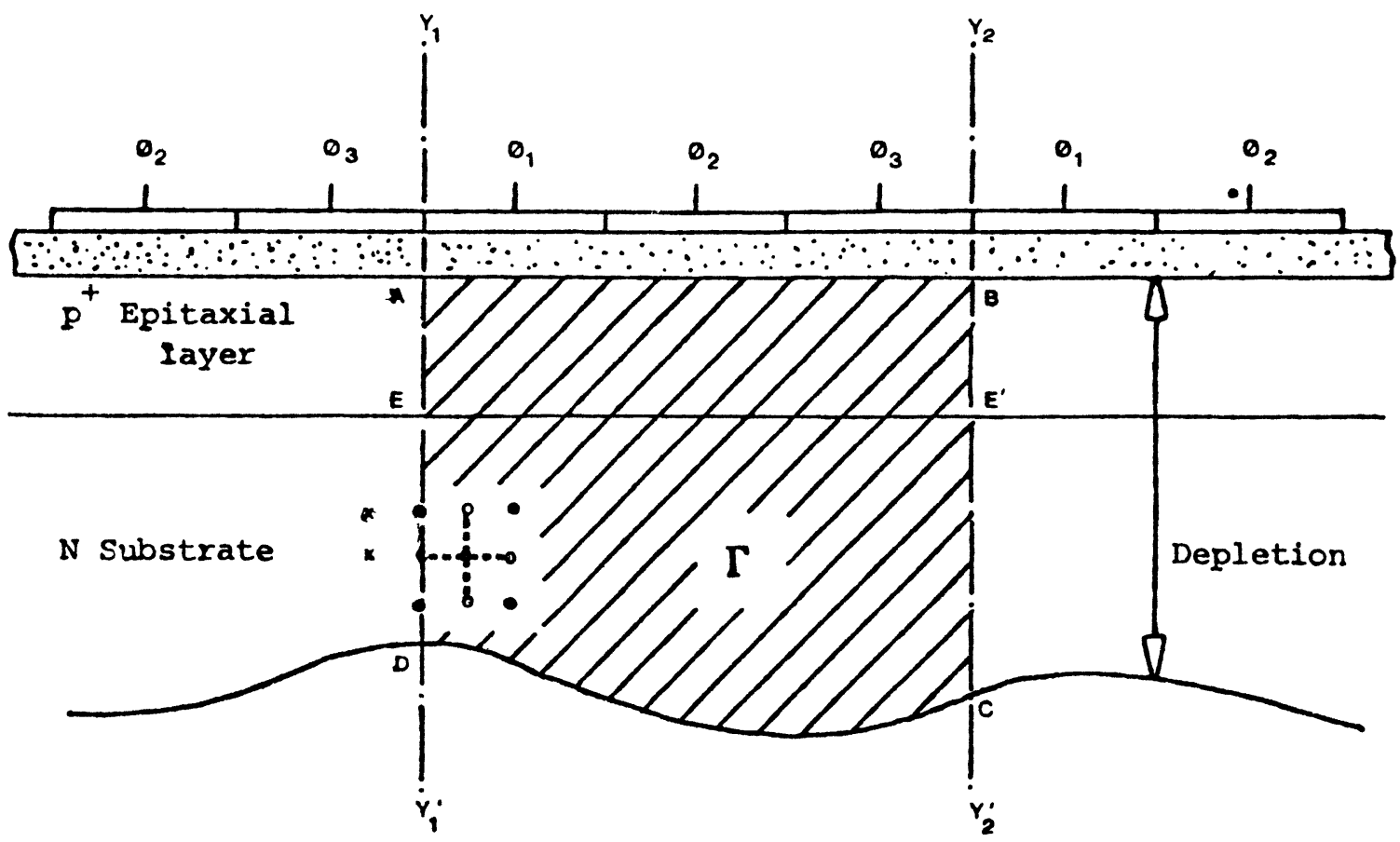

FIG. 2. - Poisson's equation is solved in $\Gamma(\mathrm{ABCD})$ and neutrality assumed below boundary DC. Part of the nodal solution mesh is also shown. 
depletion in the appropriate regions gives the operating environment for a BCCD. The depletion boundary is at DC of figure 2. Due to the cyclic operation, a three gate cell is considered to be the smallest area required for simulation, the basic cell being repeated many times to build up the complete device. Input/ Output configurations have been neglected in this simulation. The left $Y_{1} Y_{1}^{\prime}$ and right $Y_{2} Y_{2}^{\prime}$ edges of the cell are not given the usual reflecting boundary conditions,

$$
\left.\frac{\partial \varphi}{\partial x}\right|_{Y_{1} Y_{1}^{\prime}}=0 \text { and }\left.\frac{\partial \varphi}{\partial x}\right|_{Y_{2} Y_{2}^{\prime}}=0 .
$$

If equation (1) was used, the resulting gate sequence would be 3-2-1-1-2-3-3-2-1 this is not suitable for the operation of the BCCD as a 1-2-3-1-2-3-1-2-3 sequence in required, therefore the boundary conditions are specified directly from the nodal approximation used to solve Poisson's equation. The algorithm used for this solution is SOR [10] and the potential distribution is then obtained as a mesh of nodal points superimposed on the cell ABCD. Boundary conditions can be specified as follows : the potential along $\mathrm{AB}$ is found by using the thin oxide approximation [11]. Along $Y_{1} Y_{1}^{\prime}$ fictitious nodes are positioned to the left and assigned values of potential from the corresponding nodes on the right of $Y_{2} Y_{2}^{\prime}$, as these are the nodal values that would be expected if a consistent solution with adjoining cells is to be obtained. A similar condition is applied at $Y_{2} Y_{2}^{\prime}$. Comparing boundary $\mathrm{CD}$ of figure 2 with $X X^{\prime}$ of figure $1 b$, it can be seen that the variation of depletion depth is much less. Typically, for gate voltages of 1 and $10 \mathrm{~V}$ a $0.5 \mu$ to $6.0 \mu$ variation can be expected for the MOS capacitors of figure $1 b$ while the corresponding variation for the BCCD is $17 \mu$ to $18 \mu$ into the substrate material. In the bulk device interest is focused on the potential that exists in the channel but as the analysis might require $15 \mu$ to $20 \mu$ of substrate layer compared with $4 \mu$ to $6 \mu$ of epitaxial layer it is clear that the large number of nodes required in the substrate will give little additional useful information. It is possible to remove the necessity for a nodal solution in the substrate by making the assumption that it is uniformly doped (which is usually the case). The potential along $E E^{\prime}$ can be calculated as part of the SOR iterative solution giving a significant saving in the storage requirements.

Consider a P-channel device operating under the above boundary conditions with nodal potential $\psi_{i m}^{k}$ on $E E^{\prime}$ (superscript $k$ gives the iteration index), then

$$
\psi_{i m}^{k+1}=\psi_{i m}^{k}+R .
$$

In figure $3 a$ the nodal connections for node $i, m$ are shown, the SOR residual can be calculated from the difference approximation to Poisson's equation,

$$
R=\frac{\alpha+\beta}{\frac{a+b}{2}}+\frac{\gamma+E_{\mathrm{S}}}{\frac{c}{2}}+Q .
$$

where

$$
\begin{aligned}
& \alpha=\frac{\psi_{i-1, m}-\psi_{i, m}}{a}, \\
& \beta=\frac{\psi_{i+1, m}-\psi_{i, m}}{b}, \\
& \gamma=\frac{\psi_{i, m-1}-\psi_{i, m}}{c}
\end{aligned}
$$

and

$$
Q=\frac{q}{\varepsilon}\left|N_{\mathrm{A}}(y)\right| .
$$

$a, b$ and $c$ are mesh dimensions.

$E_{\mathrm{S}}$ is the normal field and is obtained from the onedimensional Poisson's equation solution for the depleted substrate regions.

$$
\frac{\mathrm{d}^{2} \psi}{\mathrm{d} y^{2}}=-\frac{q}{\varepsilon}\left|N_{\mathrm{D}}\right|
$$

Integrating with origin on $E E^{\prime}$ gives

$$
E(y)=E_{\mathrm{S}}+\frac{q}{\varepsilon} N_{\mathrm{D}} y,
$$

assuming $E=0$ when $y$ is on $\mathrm{CD}$. Integrating again and letting $\psi$ at $X X^{\prime}=\psi_{\text {ss }}$ gives

$$
\psi(y)=\psi_{0}+E_{\mathrm{S}} y+\frac{q}{2 \varepsilon} N_{\mathrm{D}} y^{2} .
$$

From (5) and (6)

$$
E_{\mathrm{S}}=\left(2 \frac{q}{\varepsilon} N_{\mathrm{D}}\left(\psi_{i, m}-\psi_{\mathrm{ss}}\right)\right)^{1 / 2}
$$

Rearranging, the position of $X X^{\prime}$ can be found as

$$
x_{\mathrm{d}}=\left(\frac{2 \varepsilon}{q N_{\mathrm{D}}}\left(\psi_{i, m}-\psi_{\mathrm{ss}}\right)\right)^{1 / 2}
$$

where $x_{\mathrm{d}}$ is the depletion depth for nodal points on the boundary.

Figure $3 b$ shows the assumed substrate potential profile for uniform doping.

The size of the mesh used was chosen with two conflicting factors under consideration, firstly, the mesh spacing should be large in order to reduce the computational requirement. Secondly it should be small so that a reasonable accuracy is obtained a compromise had to be accepted and the results presented here are for a mesh of 3000 points.

3. The transient algorithm. - Once the Poisson/ Laplace's equation has been solved with assumed total depletion (except at the designated nodes in the channel where the full neutralising majority carrier density 


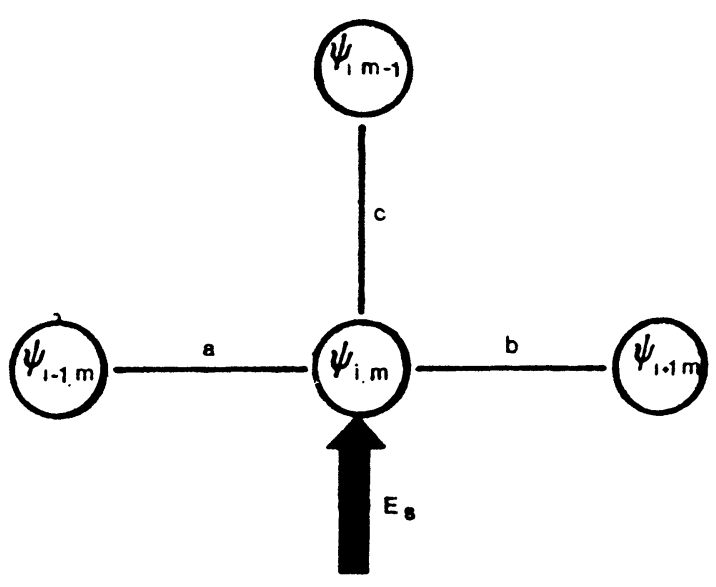

a)

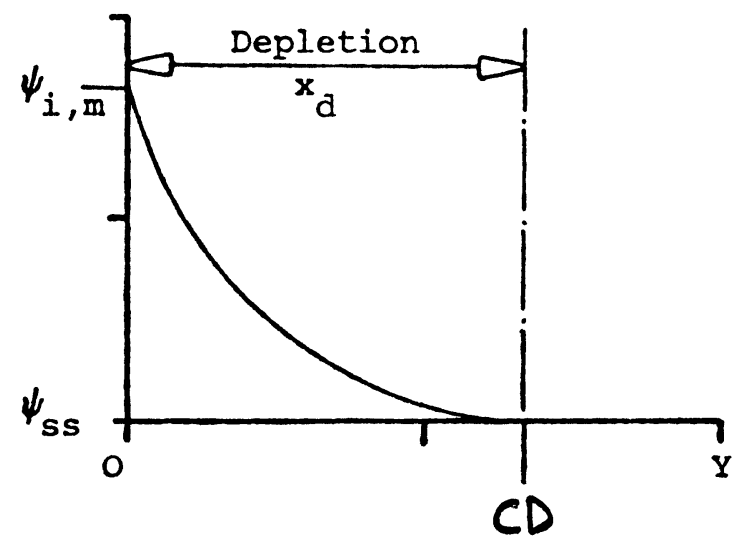

b)

Fig. 3. - a) For solution at lower boundary $\psi_{i m}$ adjacent nodes $\psi_{i, m+1}, \psi_{i-1, m}$ and $\psi_{i+1, m}$ are used with calculated substrate field $\left.E_{\mathrm{S}} . b\right)$ Substrate potential distribution versus distance, depletion boundary is at $X X^{\prime}$ and $x_{\mathrm{d}}$ is depletion depth.

resides) the algorithm examines the node pairs on the channel which link neutral and depleted regions. Poisson's equation is solved at these nodes which are depleted and Laplace's equation at the nodes designated to represent the channel in which it is assumed that,

$$
\left|N_{\mathrm{A}}\right|-p=0 \text {. }
$$

The channel is arbitrarily deemed to exist in this initial position, but as this is not a steady state, the transient algorithm will allow the charge to take up its correct position so that the device may then subsequently operate as a BCCD. Since current continuity is maintained motion of the charge packet is determined by the movement of its periphery, a packet may sub-divide if the conditions require it in which case the algorithm would consider each as a separate entity.

A network of cells and nodes is presented in figure 4, cell $\mathrm{A}$ is uncharged and bounds the channel, cell B

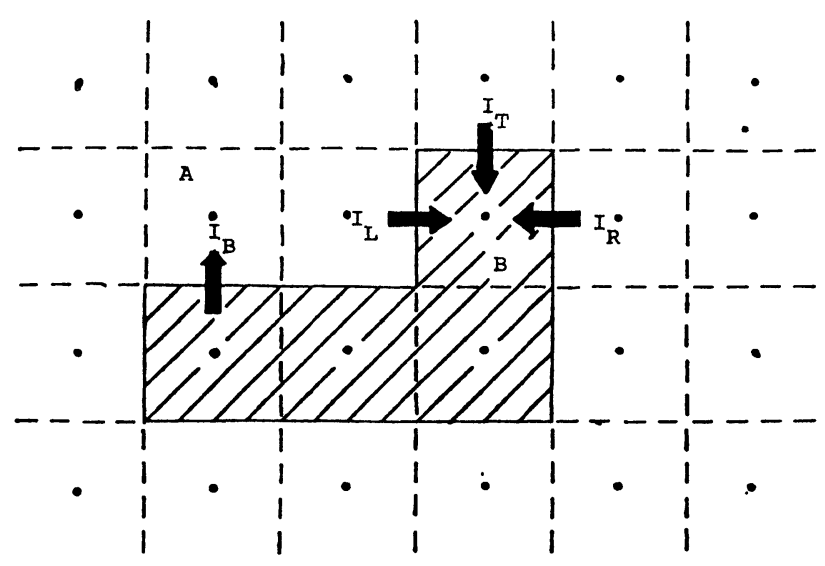

FIG. 4. - Array of cells for solution of current continuity equation. Node $\mathbf{A}$ is a depleted node adjacent to channel and $\mathbf{B}$ is a peripheral channel node.

is in the channel and charged but on the periphery. All possible current components entering each cell are shown (solid arrows). The time taken for each interface node to charge to its full value from these currents is calculated from the current continuity equation.

$$
\frac{\partial p}{\partial t}=\nabla \cdot\left(\mu_{p} p \nabla \psi+D_{p} \nabla p\right)
$$

Neglecting the diffusion component equation (9) becomes

$$
\frac{\partial p}{\partial t}=\nabla \cdot p \mu_{p} \nabla \psi=\nabla \cdot \frac{I}{A}
$$

rearranging (10) to calculate charging time

$$
t_{\mathrm{c}}=\frac{Q}{\nabla . I}
$$

where $Q$ is total charge to be held in a cell. $\nabla . I$ can be discretised as $\sum I_{\mathrm{S}}$, i.e. the sum of current components, and $I_{S}$ is the current entering a cell through each side per unit length. Hence,

$$
\nabla . I=\sum I_{\mathrm{S}}=I_{\mathrm{L}}+I_{\mathrm{R}}+I_{\mathrm{T}}+I_{\mathrm{B}}
$$

Using (10) and (12) $I_{\mathrm{S}}$ can be written

$$
I_{\mathrm{S}}=\mu\left\{\frac{Q_{\mathrm{S}}+Q_{0}}{2}\right\}\left\{L_{\mathrm{S}}\right\}\left\{\frac{\psi_{\mathrm{S}}-\psi_{0}}{L_{\mathrm{S}}}\right\},
$$

where $S$ varies over each side of the cell and $L_{\mathrm{S}}$ is the side length.

The charging times $t_{\mathrm{c}}$ for the peripheral nodes are calculated and stored in a list. The time step is calculated by examining the charging time list, it is set to 1.5 time that in which the most rapidly charging node is filled. This node and any other which will charge in twice this time is designated for a change of state. These two factors (1.5 and 2.0) were chosen 
so that a reasonable transient picture may be obtained If the time step is too small very few nodes change at any one time and the solution time becomes excessive. A time step which is too large will imply that all peripheral nodes moove and no meaningful solution is obtained. These factors are not limiting, a samll variation in either will produce an insignificant difference in the overall charge transition time. Once the node switching has been carried out the Poisson equation is resolved and the iterative cycle begins again. Figure 5 gives a flow diagram of the solution algorithm.

It should be emphasised that it is only nodes which

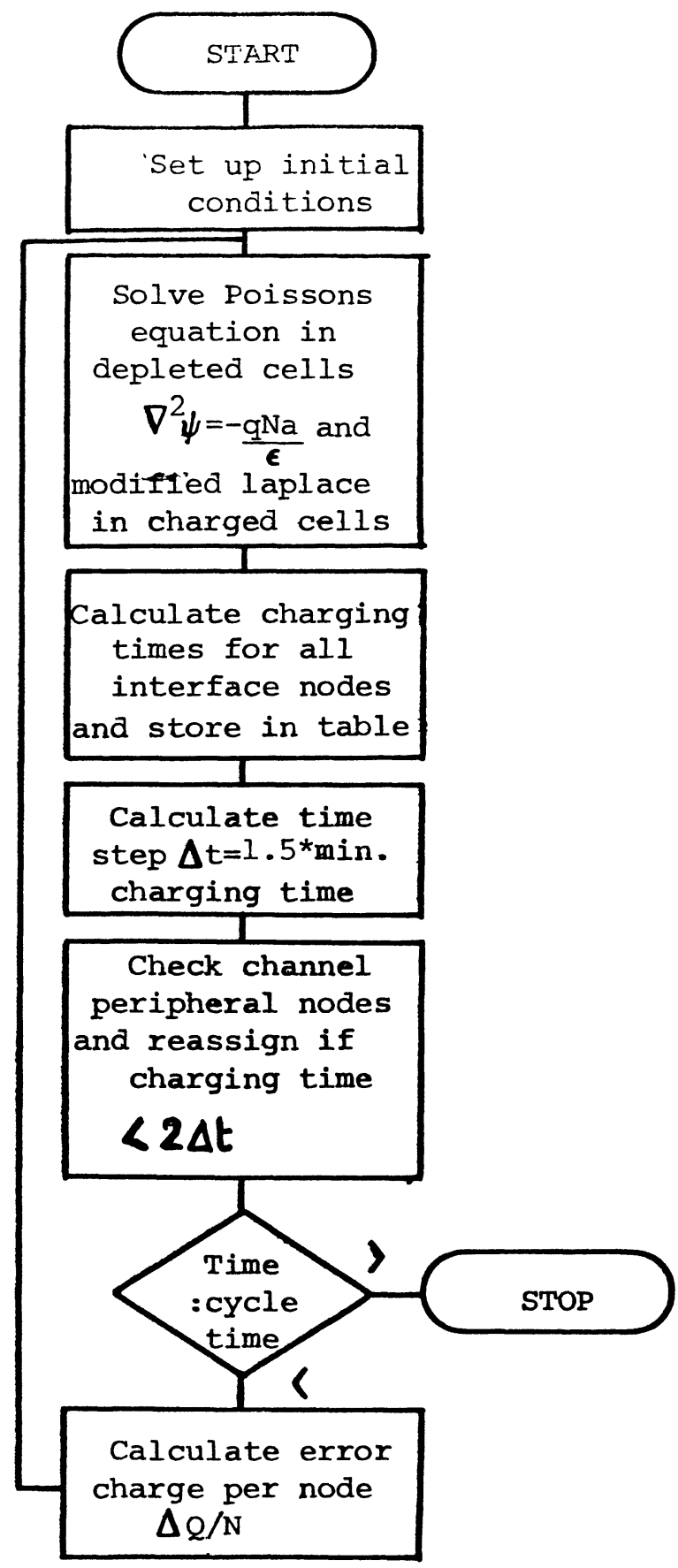

Fig. 5. - Flow diagram of transient BCCD analysis algorithm. have a positive charging current that are considered for a change of state. This is to allow the same decision rule to be applied to both channel and depleted nodes which are flagged for switching. It is not important to distinguish between nodes set for a change of state that lie adjacent to or on the charge periphery. Any node which is set to change can only change to a node of opposite type.

4. A one-dimensional exact simulation. - In order to evaluate the accuracy of the two-dimensional model a one-dimensional steady state exact simulation has also been developed with which a comparison can be made.

The behaviour of semiconductor devices can be calculated from the solution of the equations

$$
\begin{aligned}
\nabla^{2} \psi & =-\frac{\rho}{\varepsilon}\left(\left|N_{\mathrm{A}}-N_{\mathrm{D}}\right|+p-n\right), \\
\frac{\partial n}{\partial t} & =G_{n}-R_{n}+\frac{1}{q} \nabla \cdot J_{n} \\
\frac{\partial p}{\partial t} & =G_{p}-R_{p}-\frac{1}{q} \nabla \cdot J_{p}
\end{aligned}
$$

and

$$
\begin{aligned}
& J_{n}=-q \mu_{n} n \nabla \psi+q D_{p} \nabla n \\
& J_{p}=-q \mu_{p} p \nabla \psi-q D_{p} \nabla p .
\end{aligned}
$$

Using the normalised equations in De Mari [12] and Gummel's formulation [13] and with quasifermi potentials $\varphi_{p}, \varphi_{n}$, equations (14) to (18) can be reduced to form a set of three non-linear partial differential equations in three variables $\psi, \varphi_{p}$ and $\varphi_{n}$. For a steady state analysis assuming no generation and a Hall-Shockley-Read [14] recombination model the three equations are

$$
\begin{gathered}
\nabla^{2} \psi=Q+e^{\varphi_{p}-\psi}-e^{\psi-\varphi_{n}}, \\
0=\nabla \cdot e^{\psi} \nabla e^{-\varphi_{n}}-\frac{(p n-1)}{\tau_{n}(p+1)+\tau_{p}(n+1)}, \\
0=\nabla \cdot e^{-\psi} \nabla e^{\varphi_{p}}-\frac{(p n-1)}{\tau_{n}(p+1)+\tau_{p}(n+1)},
\end{gathered}
$$

where $p=e^{\varphi_{p}-\psi}$ and $n=e^{\psi-\varphi_{n}}$. Equations (19)(21) are solved using a modified form of the nonlinear Newton method [15] for $\psi, \varphi_{p}$ and $\varphi_{n}$. This particular numerical approximation is found to be very stable and converges from virtually any initial state. Internodal potential differences of the order of $3 \mathrm{~V}$ are quite acceptable, allowing much fewer nodes to be used in areas of high potential gradients. As the BCCD does not have a true steady state mode of operation special, boundary conditions must be specified at the $\mathrm{Si} / \mathrm{SiO}_{2}$ interface and within the channel. The boundary condition in the channel is specified so as to maintain the appropriate substrate reverse bias. Its initial position is not critical and the final point could be found by an iterative procedure. 
At the $\mathrm{Si} / \mathrm{SiO}_{2}$ interface the usual boundary conditions,

$$
\frac{\partial \varphi_{p}}{\partial x}=\frac{\partial \varphi_{n}}{\partial x}=0
$$

were found unsatisfactory as deep depletion is not satisfied by (22). To overcome this, values of $\varphi_{p}$ and $\varphi_{n}$ on the interface are give values fixed relative to $\psi$ which remains free,

and

$$
\varphi_{p \mathrm{~s}}=\psi_{\mathrm{s}}-\xi
$$

$$
\varphi_{n \mathrm{~s}}=\psi_{\mathrm{s}}+\xi,
$$

where $\xi$ is a potential arbitrarily chosen so as to retain surface depletion of both majority and minority carriers. This assumption can be considered valid as the main area of interest exists $4 \mu$ to $6 \mu$ below the device surface. Experimental verification for this showed that only a few mesh spacings are required

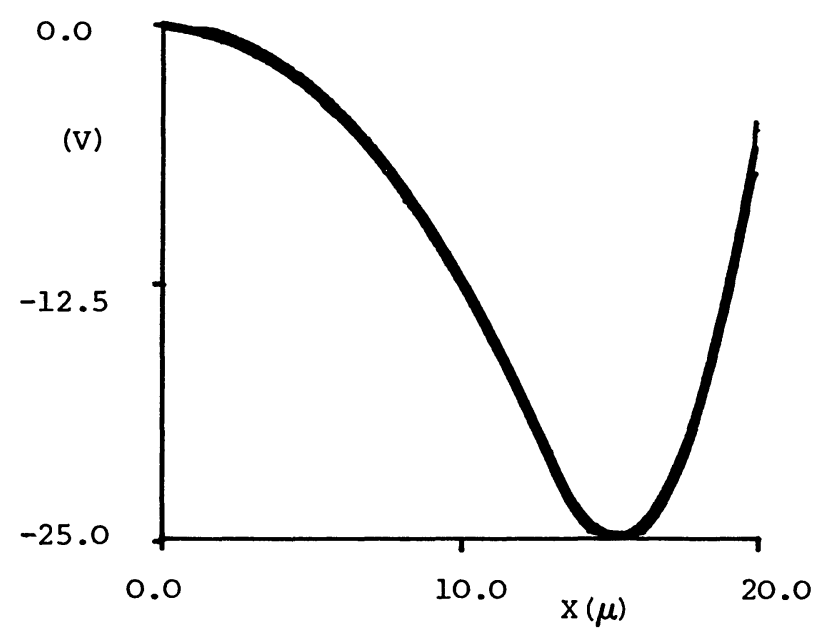

a)

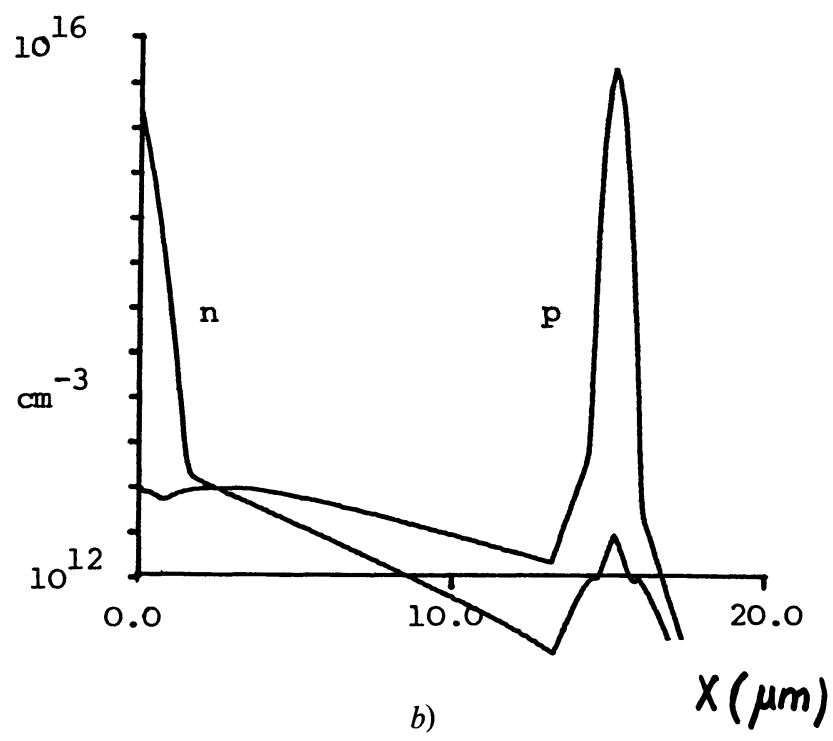

FIG. 6. - a) Potential vs. distance for device specified in table II, $V_{\mathrm{g}}=-2.5 \mathrm{~V} . b$ ) Hole and electron densities $v s$. distance. before the effect of a change in $\xi$ becomes indistinguishable in $\psi, \varphi_{p}$ or $\varphi_{n}$. Figures 6 and 7 give computer simulation results obtained by this method for a large and small packet of mobile charge respectively. Examination of carrier densities, figures $6 b$ and $7 b$ indicates that transition from neutral channel to $90 \%$ depletion is obtained in a short length thus validating the assumptions made in this paper. Dale [16] gives a detailed analysis of errors arising in the depletion approximation.

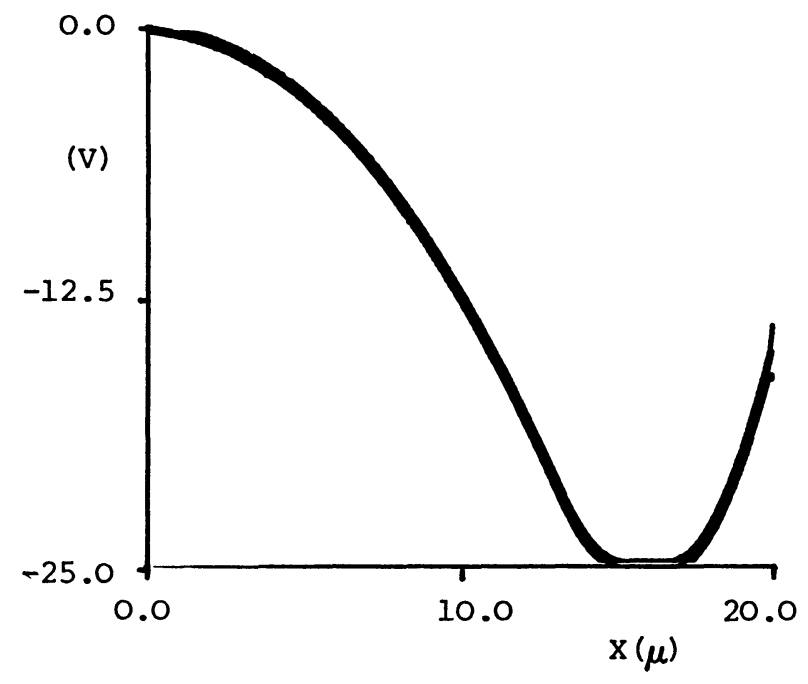

a)

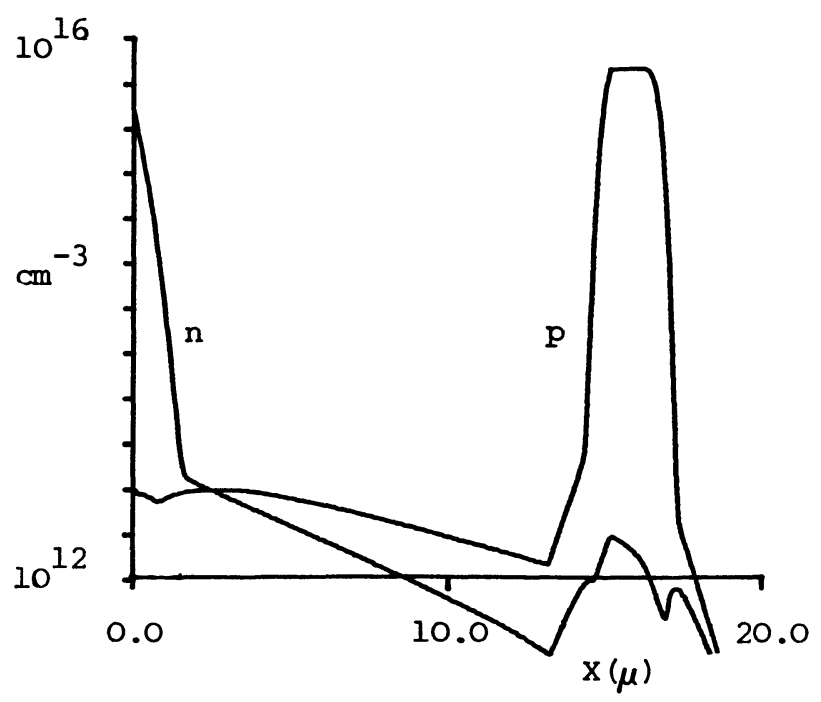

b)

Fig. 7. - a) Potential vs. distance for device specified in table II, $V_{\mathbf{g}}=-12.5 \mathrm{~V} . b$ ) Hole and electron densities $v s$. distance.

5. Results. - In figures 8 and 9 the potential in the 3 gate cell is presented as a surface function plotted in 3 dimensional form, for the device parameters listed in table I. Figure 8 shows the effect of a $15 \mathrm{~V}$ pulse on the second gate producing a potential peak. Here the potential variation within the well which assists in the rapid transfer of charge can be observed. 


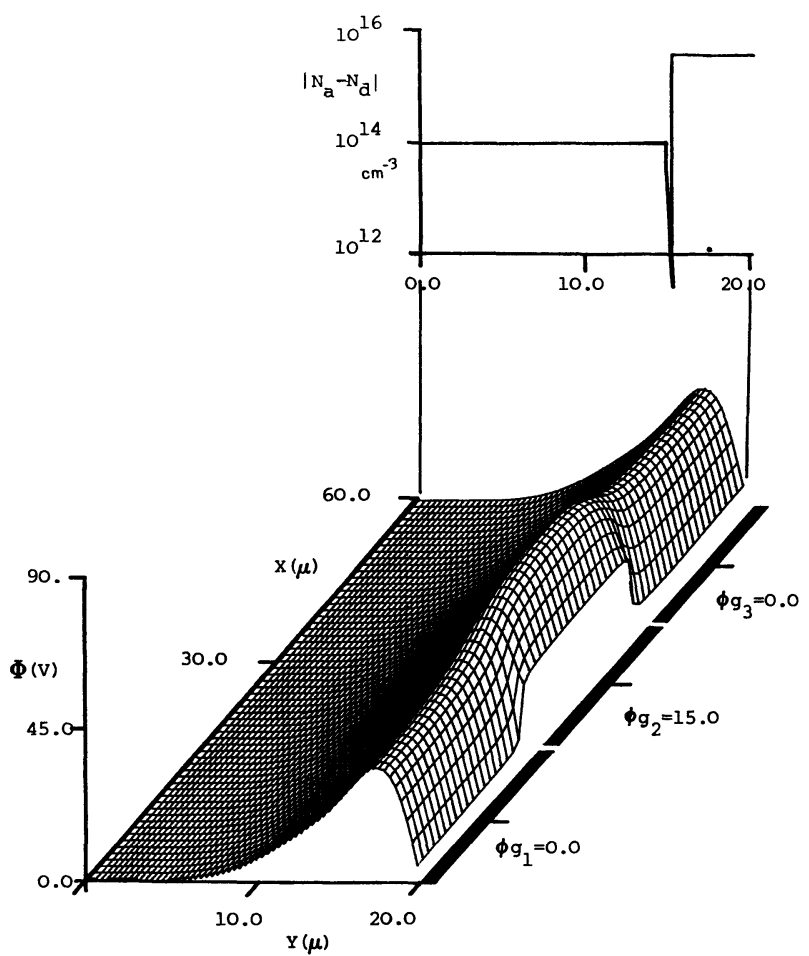

FIG. 8. - Steady state potential distribution and impurity profile for $\mathrm{N}$ channel BCCD with no mobile charge.

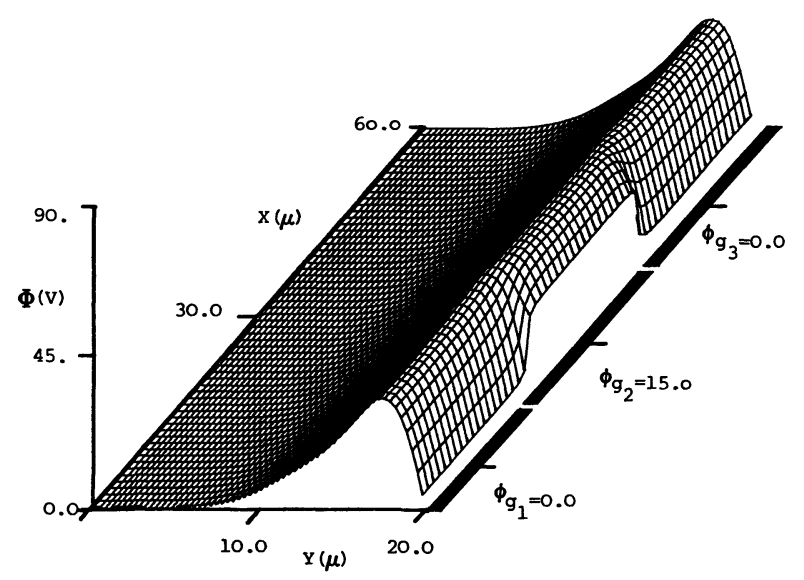

FIG. 9. - Steady state potential distribution for BCCD with $32 \mathrm{pC} / \mathrm{cm}$ mobile charge packet.

\section{TABLE I}

Epitaxial thickness

Oxide thickness

Gate length

Inter electrode gap

Substrate doping $N_{\mathrm{A}}$

Epitaxial doping $N_{\mathrm{D}}$

$$
\begin{gathered}
5.0 \mu \mathrm{m} \\
0.1 \mu \mathrm{m} \\
20.0 \mu \mathrm{m} \\
<1 \mathrm{mesh} \text { spacing } \\
1 \times 10^{14} \mathrm{~cm}^{-3} \\
2 \times 10^{15} \mathrm{~cm}^{-3}
\end{gathered}
$$

The well in figure 9 has been filled with a packet of mobile charge. This is a steady state representation of the storage phase of device operation. It is possible

from this simple picture to calculate the maximum charge which the device would be able to store, i.e. before the well potential is less than that of the adjacent uncharged ones. A typical maximum charge for the device of table I is $32 \mathrm{pCm}^{-1}$. Figure 10 illustrates a device in which transfer was not completed successfully, the gate transfer operation was completed in $0.27 \mathrm{~ns}$ but the charge transfer has not been completed in $0.35 \mathrm{~ns}$ when the movement cycle restarts. This sequence also demonstrates the problem that can be encountered when the necessary clock overlap time is absent or of too short an interval. It can be seen that a portion of the charge is left under both the first and second gates. As the potential under the first begins to fall again due to the proximity of the next charge packet this charge breaks away from the
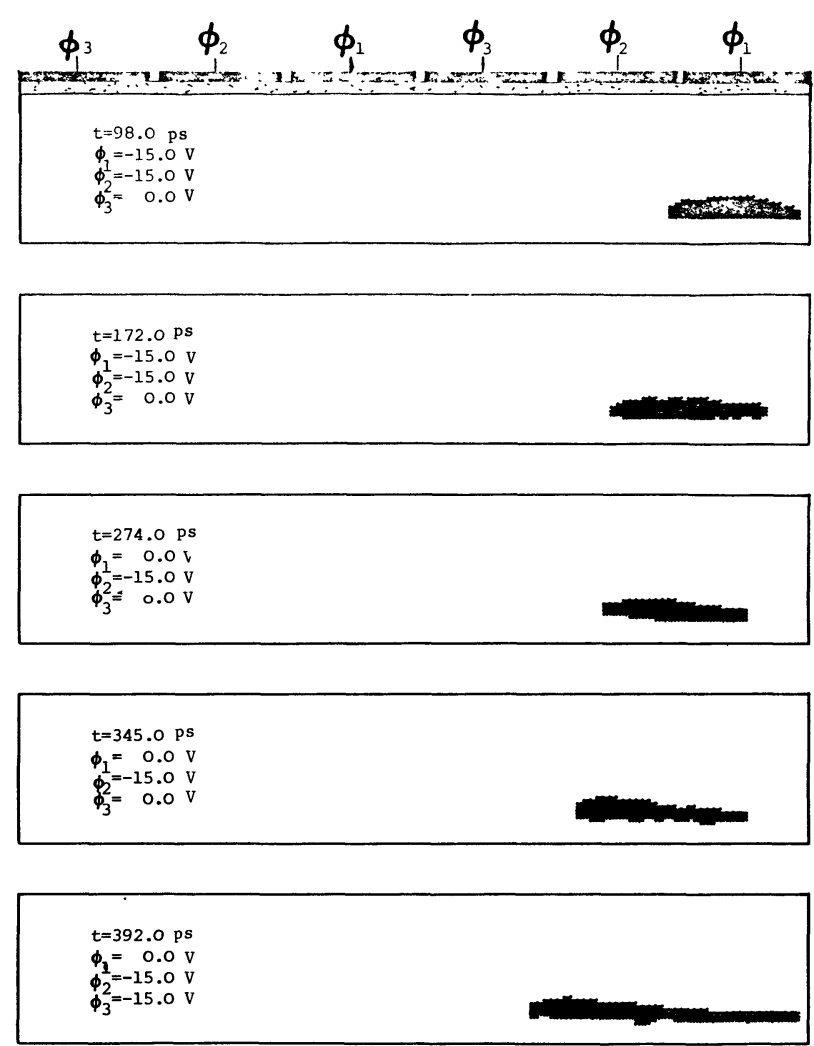

$\mathrm{t}=422.0 \mathrm{ps}$

$\phi_{1}=0.0 \mathrm{~V}$

$\phi_{3}=-15.0 \mathrm{~V}$

FIG. 10. - Charge motion in $\mathrm{p}$ channel device showing high transfer inefficiency.

TABLE II

Epitaxial thickness

Oxide thickness

Substrate thickness

Substrate doping $N_{\mathrm{D}}$

Epitaxial doping $N_{\mathrm{A}}$

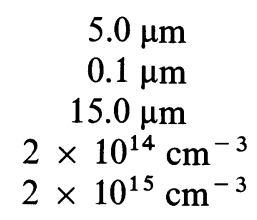


main packet and then joins up with the next as it is transferred back to the first gate of the analysis cell.

The above results from the simulation were obtained on a mesh of 3000 points arranged in an array of 60 by 50 , thus for the device structure analysed each cell has an error of $0.1 \mu \mathrm{m}^{2}$. It would be possible to reduce this size and so improve the accuracy of the technique but as the algorithm is primarily intended for rapid device simulation it is desirable that the computation time be as short as possible. Some figures on this :

When executed on a CDC 7600 the program will complete a three gate transfer cycle, including initial set up of channel position in 127s. This time could be reduced by assuming that the depletion depth variation is negligible. Using a predetermined depth the solution may be speeded up by between two and five times.

6. Conclusions. - An algorithm has been developed for the simulation of the transient response of a bulk channel C.C.D. Assumptions made, notably that of a depletion approximation to define the channel boundary, allow a rapid analysis to be completed. Errors arising were shown to be small in a comparison with an exact one-dimensional simulation. The results presented show the expected operation of an optimum structure. However, with small modifications the algorithm can be used to predict the performance of fabricated devices. The main advantages of this technique are its immunity to numerical instability and its adaptability to studying structures with large potential differences.

One problem that was encountered, alough the reduced computation requirements allow a rapid evaluation of new device structures it is still slow when compared with a normal SOR convergence rate. This is due to the nonlinear terms introduced with the inclusion of the substrate boundary field. It is possible that this may be overcome with the use of algorithms more suited to mildly nonlinear problems.

\section{References}

[1] Boyle, N. S. and Smith, G. E., Bell Syst. Tech. J. 49 (1970) 587.

[2] Walden, R. H., Krambeck, R. H., Strain, R. J., McKenna, J., SCHRYer, N. L. and Smith, G. E., Bell Syst. Tech. J. 51 (1972) 1635.

[3] McKenna, J. and Schryer, N. L., Bell Syst. Tech. J. 52 (1972) 669.

[4] McKenna, J. and Schryer, N. L., Bell Syst. Tech. J. 52 (1973) 1765.

[5] El Sissi, H. and CoBbold, R. S., IEEE Trans. Electron. Devices 21 (1974) 437.

[6] El-Sissi, H. and CoBbold, R. S., IEEE Trans. Electron. Devices 22 (1975) 77.

[7] Kent, N. H., Bell Syst. Tech.J. 52 (1973) 1009.

[8] Armstrong, G. A. and Magowan, J. A., Electron. Lett. 6(1970) 313.
[9] Armstrong, G. A. and Magowan, J. A., Solid-State Electron. 14 (1971) 723.

[10] VARGA, R. S., Matrix Iterative Analysis (New Jersey : Prentice Hall Inc.) 1962, 97.

[11] Magowan, J. A., Ph.D. Thesis Q.U.B. (1968) 44.

[12] De MarI, A., Solid-State Electron. 11 (1967) 33.

[13] Scharfetter, D. L. and Gummel, H. K., IEEE Trans. Electron. Devices 16 (1969) 64.

[14] Hall, R. N., Phys. Rev. 87 (1952) 387, Shockley, W. and Read, W. T., Phys. Rev. 87 (1962) 835.

[15] Ortega, J. M. and Rheinboldt, W. C., Iterative Solution of Nonlinear Equations in Several variables (New York : Academic Press) 1970, 181.

[16] DaLE, B., IEEE Trans. Electron. Devices 23 (1976) 275. 